\title{
Tanashi, Tokyo 188
}

\section{Japan}

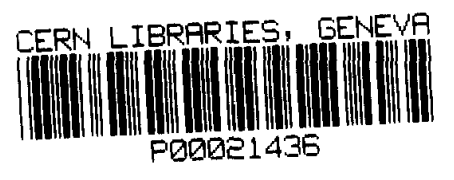

\section{A Simple Relation among the Quark Masses}

\author{
Hidezumi Terazawa
}

Institute for Nuclear Study, University of Tokyo,

Midori-cho, Tanashi, Tokyo 188, Japan 



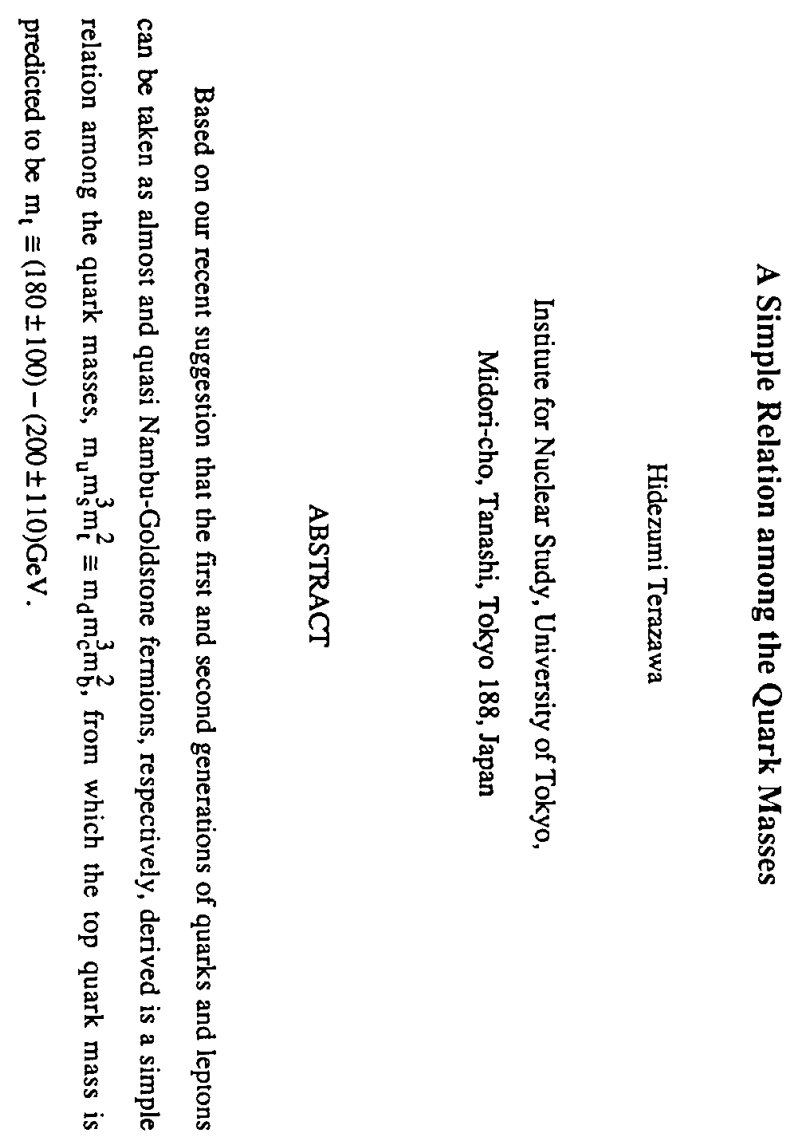

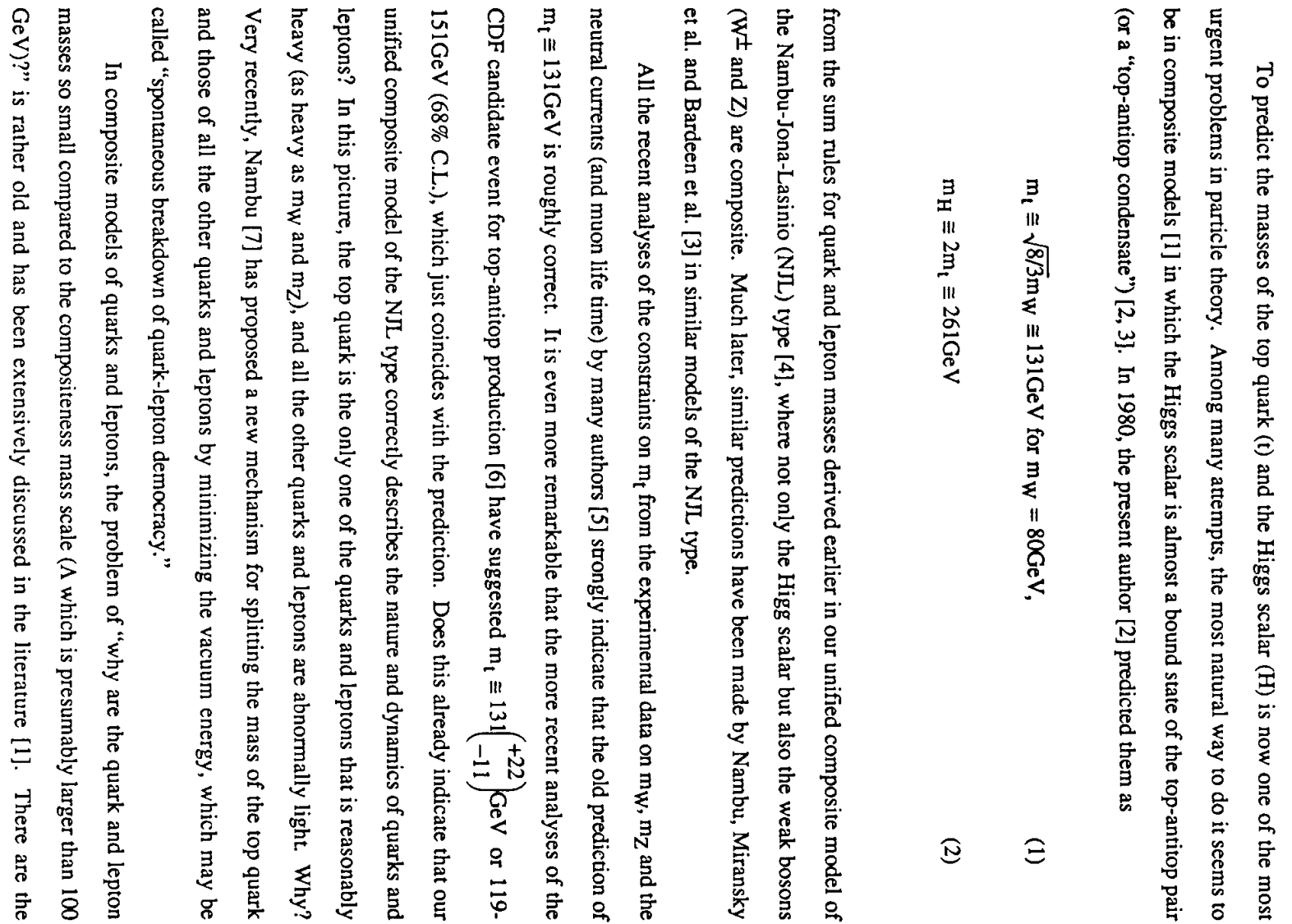




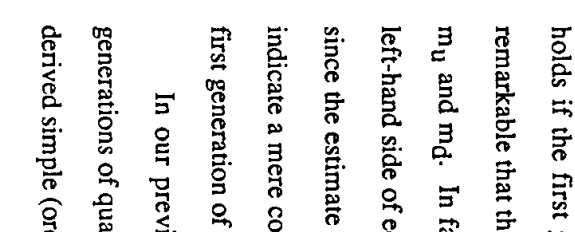

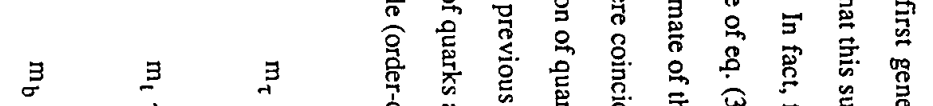

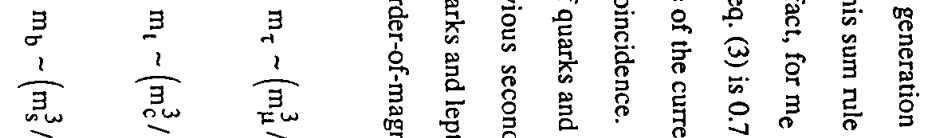

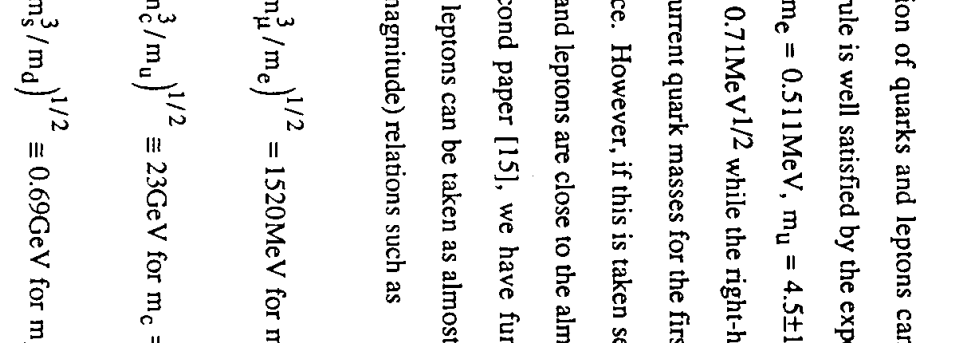

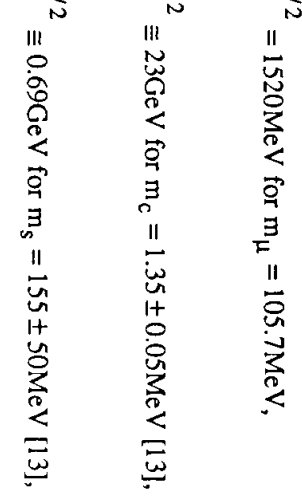

ब $) ~ E$

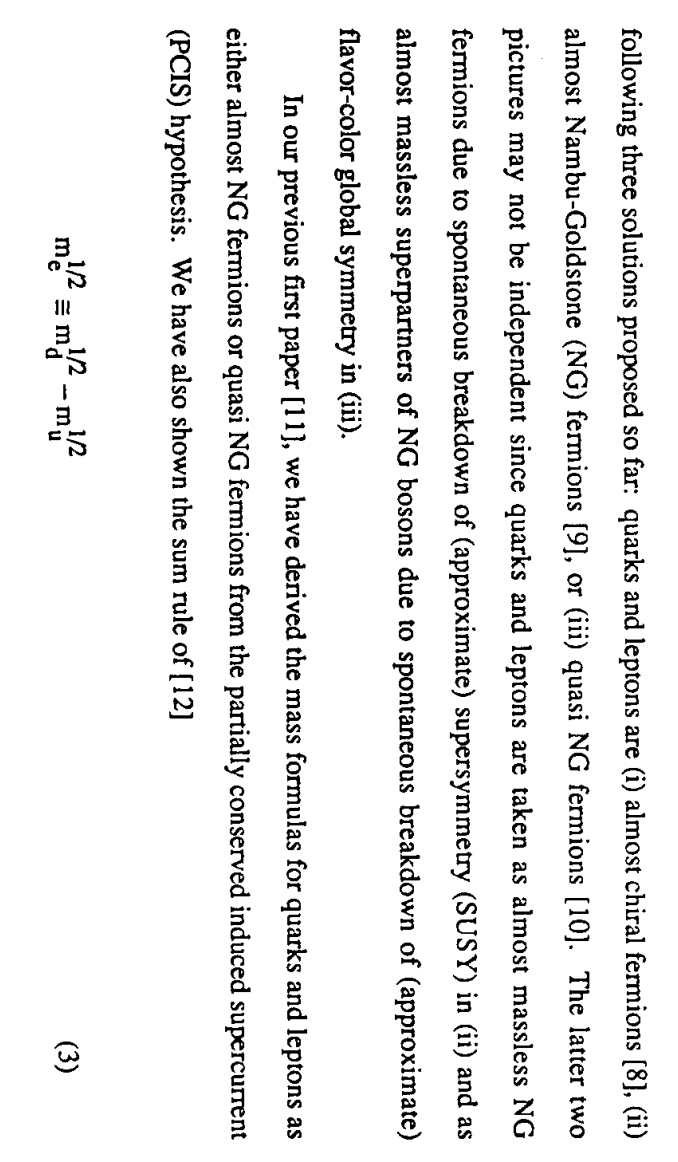

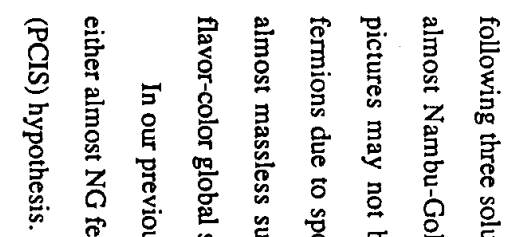

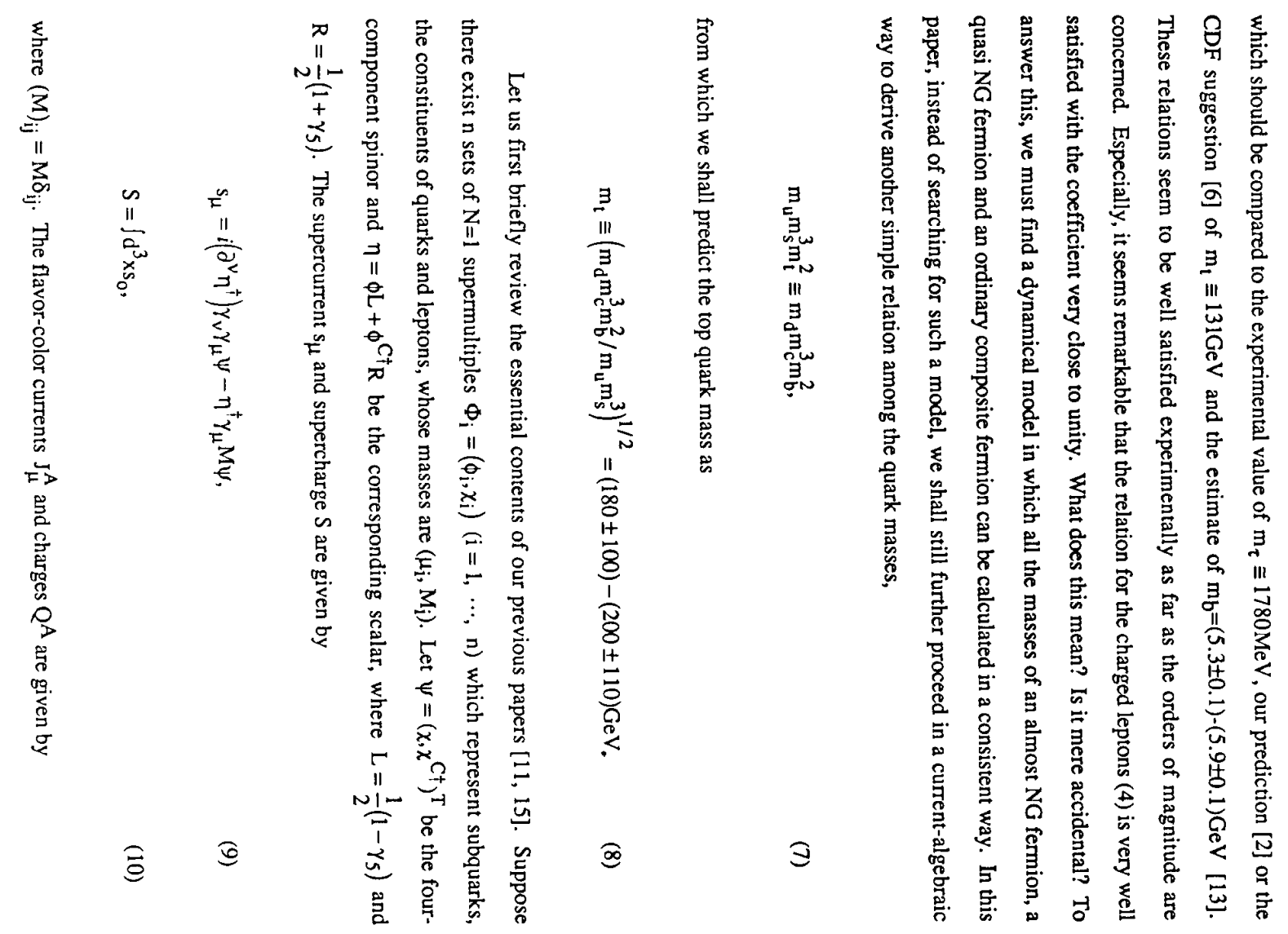



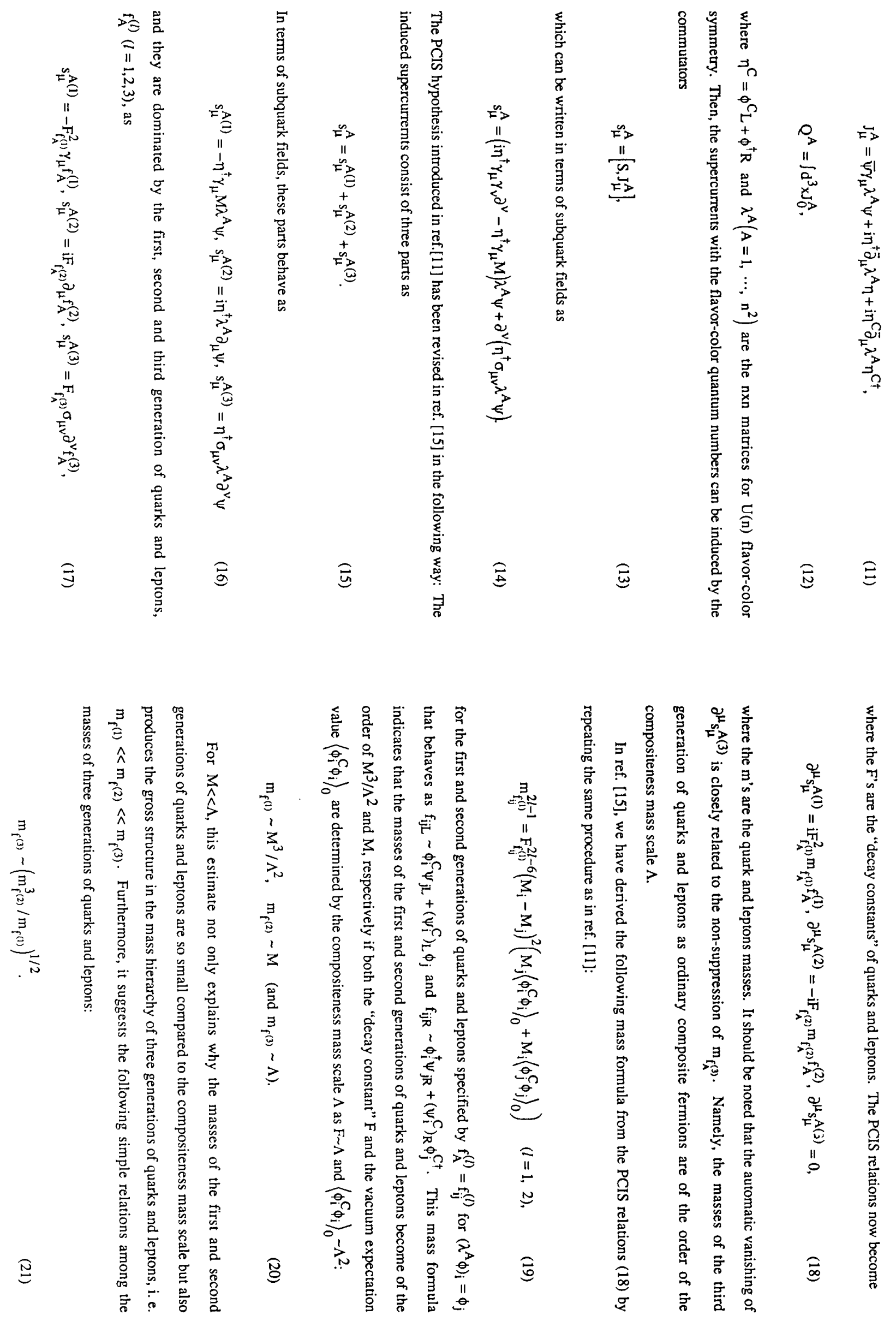

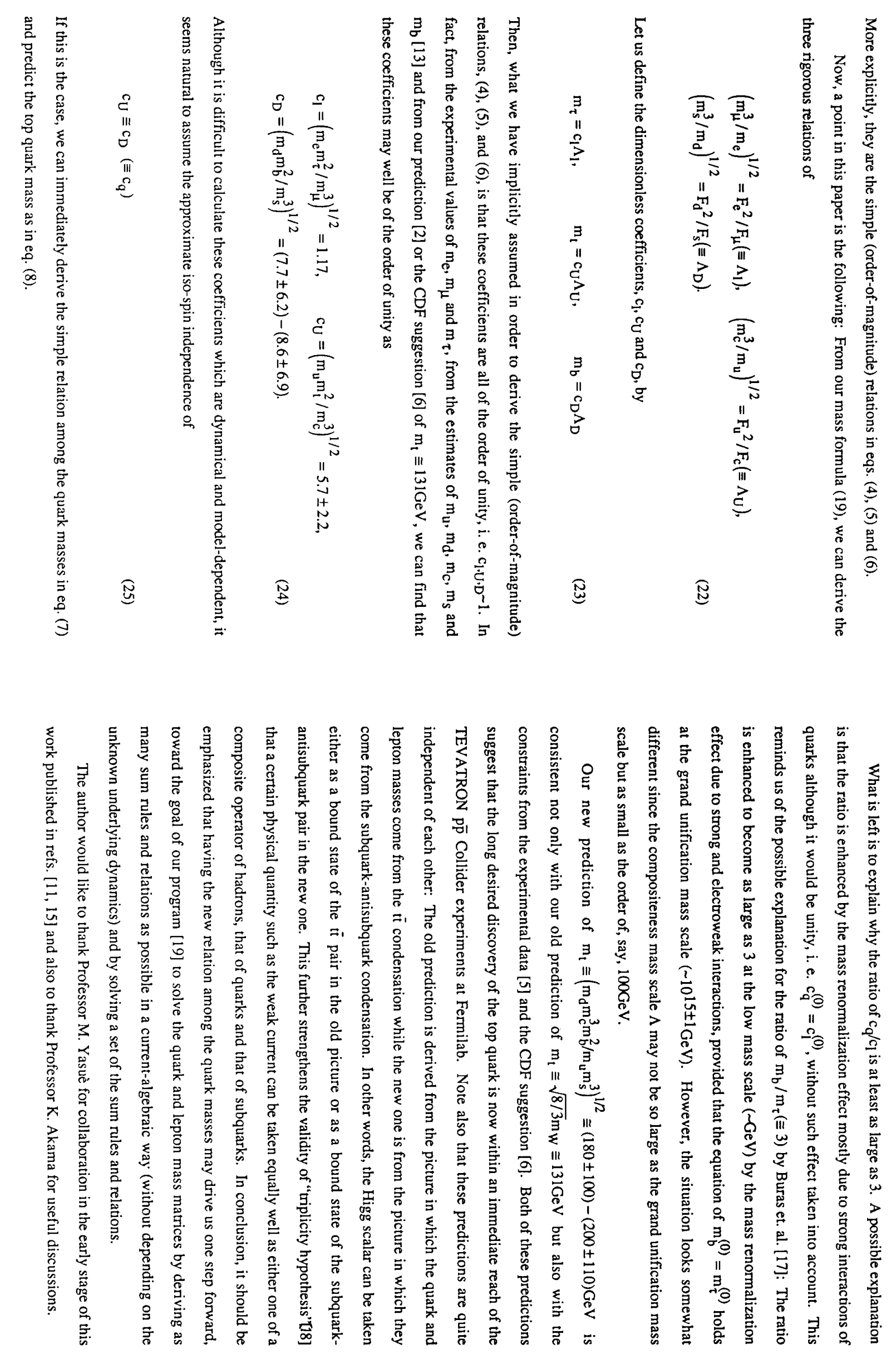

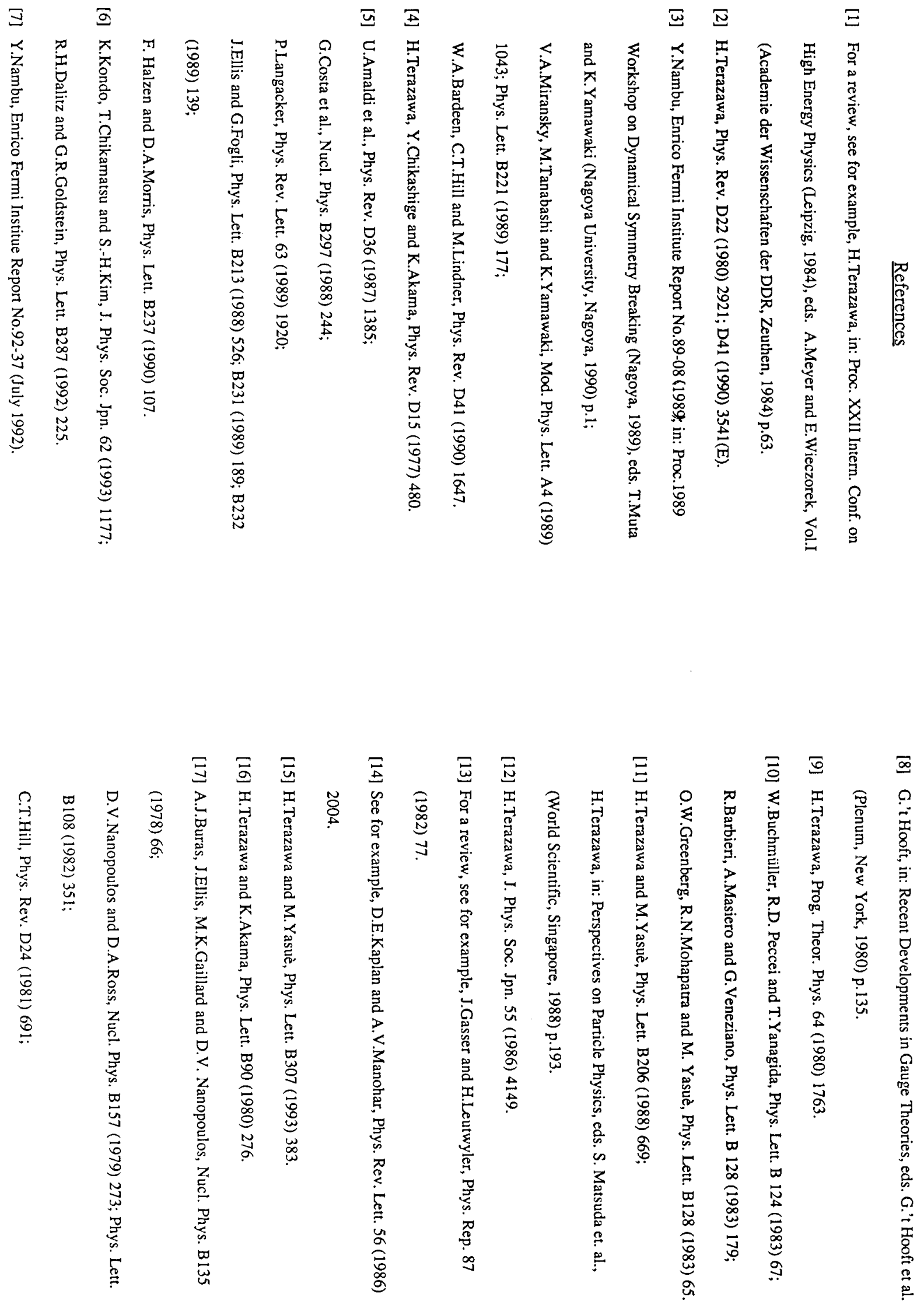


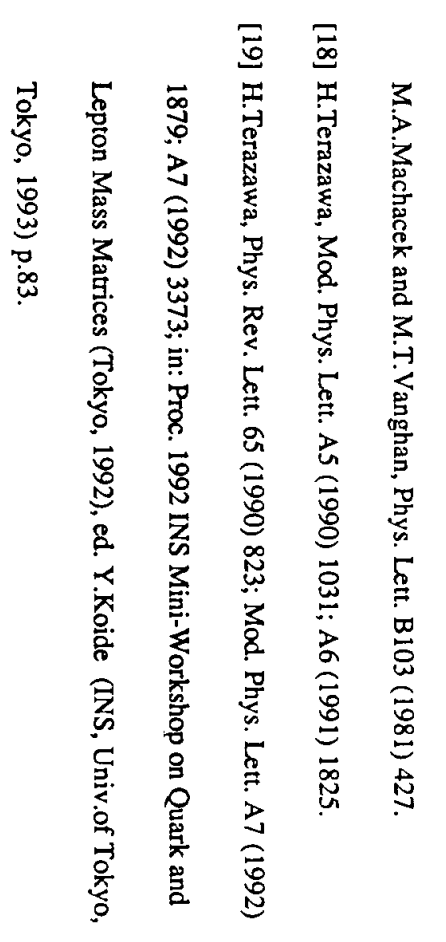

